\title{
ANXIETY, ILLUSORY PATTERN PERCEPTION AND CONSPIRACY BELIEFS DURING THE COVID-19 PANDEMIC
}

\begin{abstract}
This study investigated the relationship between the anxiety provoked by threatening events in society like the Covid-19 pandemic, and illusory pattern perception, with conspiracy beliefs. Using an experimental design, in Study 1 high vs. low anxiety was manipulated, while in Study 2 we manipulated intuitive pattern search, with the findings supporting the assumption that greater anxiety and higher intuitive pattern search lead to an increase in conspiracy beliefs. In order to prevent the detrimental effects of beliefs in conspiracy theories on the individual and societal levels, we recommend transparent information and pre-warning, as well as a focus on critical thinking in education.

Keywords: societal events, anxiety, intuitive pattern search, illusory pattern perception, conspiracy beliefs, Covid-19 pandemic
\end{abstract}

\section{Introduction}

Consequential events in society that provoke distress and anxiety, such as natural disasters, terrorist strikes, wars, economic crises and rapid societal changes, are followed by the emergence of conspiracy theories (van Prooijen et al, 2018; Douglas, 2021). The Covid-19 pandemic is no exception. Countless theories as to the origin of the SARS-CoV-2 virus and the reasons for its spread have emerged (Douglas, 2021; van Prooijen, 2020), especially on social media. The most widespread conspiracy theories in social media state, among others, that the coronavirus is a fraud, the vaccine against it is some biological weapon, or that particular elites intentionally released the coronavirus and are insisting on vaccination with a view to taking full control over the people.

A conspiracy theory is a psychosocial phenomenon, defined as the conviction that a group of actors has secret meetings for the purpose of

\footnotetext{
* Ognen Spasovski, PhD, Professor, University Cyril and Methodius in Trnava, Slovak Republic; Slavka Demuthova, PhD, Docent, University Cyril and Methodius in Trnava, Slovak Republic; Vesna Kuzmanovic, PhD, Researcher and CEO, Stratum RED, Skopje, Republic of North Macedonia. DOI: 10.51936/tip.58.3.1333-1149
} 
attaining some malevolent goal (Bale, 2007; Douglas, 2021). These theories are involved in almost every significant event in society (Moscovici, 1987), thus calling upon the social sciences to investigate the underlying reasons. The Error Management Theory (Haselton and Nettle, 2006; 2000; Rządeczka, 2018) proposes that when judgements are made under uncertainty, and the costs of false negative and false positive errors are asymmetrical, selection over evolutionary history should favour a bias towards making the least costly error. In turn, this mechanism will increase people's tendency to believe in explanations that, while almost costless to them, are probably false. Van Prooijen and van Vugt (2018) suggested an additional evolutionary-rooted explanation of conspiracy beliefs. These authors proposed that conspiracy beliefs may be a by-product of several psychological adaptations as evolved mechanisms during the human history of group living. One of these adaptations is the predisposition to recognise patterns in the environment, which, in this context, may be reflected in perceiving connections between various events related to Covid-19 that, in reality, are probably not connected. Another adaptation is to detect agency in the events we perceive, like the belief that some institutions, companies or organisations - such as the WHO - intentionally spread the virus with a view to making a profit, or to inject nano-chips into human bodies in order to establish full control over people. Finally, one evolved adaptive mechanism concerns the human coalitional mind, with a function to alert our ancestors to the possibility that other people or groups are forming malevolent coalitions against them. The function of this adaptation is to urge people to prepare for action and defence from such others.

According to Douglas (2021), people are drawn to conspiracy theories when important psychological and social needs are not being met. She defines three sets of these needs. The first are epistemic needs, including the desire to satisfy curiosity and avoid uncertainty. Findings in this domain suggest that conspiracy beliefs are linked to the search for patterns and meaning in events, even when no such patterns or meanings exist (van Prooijen et al., 2018). The second set of needs are existential, including the motivation to restore a threatened sense of security. Here, people who feel anxious or worried are more likely to believe in conspiracy theories (Grzesiak-Feldman, 2013; Václaviková and Selecká, 2018). The third set are social needs, including the desire to hold one's self and one's groups in a positive regard.

Given the above explanations, we may assume that the time of the pandemic has been more than fruitful for conspiracy theories to flourish. The pandemic triggers a fear of being infected with dangerous virus and provokes anxiety due to the ensuing uncertainty about the future, which may lead to changes in individual and societal dynamics. 


\section{Conspiracy beliefs, anxiety and the perception of patterns in unconnected events}

High-anxiety situations increase conspiracy thinking (Grzesiak-Feldman, 2013), making people more prone to blaming some individuals, group(s) or institution(s). Such beliefs are present in both modern and traditional societies (West and Sanders, 2003). Moreover, a large share of the human population believes conspiracy explanations because they provide both simple answers to otherwise unanswered questions and an enemy to blame for the problem at issue (Goertzel, 1994; Václaviková et al., 2016). Conspiracy beliefs help people find an explanation for anxiety-inducing events, thereby allowing them to retain a sense of safety and predictability (Bale, 2007; Leman, 2007). Obtaining an answer by believing in a particular conspiracy theory might even have a short-term calming effect in very uncertain situations like the Covid-19 pandemic (Spasovski and Kenig, 2020)

States of anxiety affect our cognitive processes by exposing them to the stronger influence of intuitive thinking (or System 1), making them prone to heuristics and shortcuts (Kahneman, 2011). People intuitively believe what they see or hear, and actually need to exert active mental effort and analytical thinking (System 2) to unbelieve it. These characteristics of cognitive functioning lead to the assumption that many people faced with threatening societal events (e.g. a virus, pandemic) will be attracted by conspiracy theories, which seem to provide the best answers to the unknown (Goertzel, 1994). Further, it is commonly assumed that when people face uncertain outcomes they become more anxious and usually more prone to perceiving patterns in environmental stimuli or events (Gilovich et al., 1985; Wilke et al., 2014). Illusory pattern perception describes when people mistakenly perceive randomly distributed stimuli or events as causally determined through a non-random process, which may be a basis for the assumption that illusory pattern perception lies at the core of the process of accepting conspiracy beliefs held by people, helping them to make sense of the world (Whitson and Galinsky, 2008).

\section{Consequences of conspiracy beliefs}

Conspiracy theories as psychosocial phenomenon bring detrimental consequences to both the individual and societal levels, with those concerning Covid-19 being no exception. They have damaging effects on the efforts undertaken by the systems in society to fight the pandemic and prevent the spread of new virus mutations. Romer and Jamieson (2020) found that belief in Covid-19 conspiracy theories was negatively associated with a perceived threat of the pandemic, complying with the government's preventive 
recommendations, and intentions to be vaccinated against Covid-19. Other researchers found believing that $5 \mathrm{G}$ networks are connected to the spread of the SARS-CoV-2 virus is related to an increase in aggressive behaviour and support for violence and anti-government protests (Jolley and Paterson, 2020; Šrol et al., 2021). Believing in conspiracy theories can also fuel intergroup conflicts, and may lead to stronger prejudice, hostility and discrimination toward the alleged conspirators as well as the legitimisation of aggression and injustice with respect to the perceived conspirators (Biddlestone et al., 2020). Finally, the notion that people who believe in one conspiracy theory tend to believe in others (Douglas et al., 2021) raises worrying assumptions that the Covid-19 pandemic might accelerate the greater presence and distribution of conspiracy beliefs, including all of their harm they bring.

\section{Study aim}

The relationship between believing in conspiracy theories and anxiety and illusory pattern perception is well elaborated in the literature. However, most studies are limited to cross-sectional designs, while research exploring their causal relationship is unsatisfactory. Considering the importance of the influence of conspiracy beliefs on social dynamics, the aim of this empirical study was to expand on the findings and investigate the causal relationship between anxiety related to the Covid-19 pandemic as consequential societal event and illusory pattern perception with conspiracy beliefs.

\section{Research overview}

We conducted two experimental studies in the present research. First, in Study 1, we manipulated the level of anxiety and tested the relationship with illusory pattern perception and conspiracy beliefs. In Study 2, we manipulated the intuitive search for patterns in dice-throw outcomes in two conditions, and tested whether participants would have differences in illusory pattern perception and also in conspiracy beliefs. In both studies, we first asked the participants for informed consent to participate in the study, with only those who answered positively being included in the sample.

\section{Study 1}

For this study, we manipulated anxiety levels in two groups (high anxiety vs. low anxiety). We also developed a measure for illusory pattern perception based on randomly generated sequences of dice-throw outcomes. Based on the assumption that, when faced with anxious uncertainty people tend to search for answers and connect unconnected events, we tested 
whether higher levels of anxiety would lead to an increased tendency to perceive illusory patterns in randomly generated dice-throw outcomes and an increased tendency for conspiracy beliefs.

\section{Method}

Participants and design. The study had a design with two conditions (high anxiety vs. low anxiety). A professional agency for market and public opinion research called "Stratum R\&D" from Skopje, Republic of North Macedonia, performed the fieldwork. Using a door-to-door approach, previously instructed survey takers collected the data while remaining physically present. Participants from all six regions of the country were selected in random order, forming a small-scale representative sample. After giving them instructions, the survey takers handed a computer tablet to the participants in order for them use it to respond to the stimuli and complete the questionnaire. A total of 187 people participated in the study (108 men, 79 women; $M$ age $=44.01$ years, $S D=11.88$, age range $=18-64)$. The participants were randomly distributed into one of the two groups. The "high anxiety" group comprised 97 participants, while the low anxiety group included 90 participants. The study took about 20 minutes to complete and the participants were rewarded with a small payment. The data were collected in the first half of April 2021, at the beginning of a massive vaccination process in the country - which started with people over 75 years of age, meaning that at the time most participants were not yet vaccinated.

Procedure and Measures. For the experimental manipulation of high vs. low levels of anxiety, we developed an adapted version of the technique used by Lerner and Keltner (2001: 153), and Whitson and Galinsky (2008). Participants initially read a one-paragraph text about the dangers and threats that the virus SARS-CoV-2 and its mutations could bring. In the end, they were asked to imagine one scenario that could develop from the Covid-19 pandemic which would be very upsetting and negative for them, and then to write a sentence or two about it. In the low-anxiety group, participants followed a similar procedure, but were asked to imagine and write about a scenario related to Covid-19 that would hold positive outcomes for them. In order to check the successfulness of the manipulation, we administered an Anxiety questionnaire after the manipulation had taken place. This instrument was an adapted version of the anxiety sub-scale of DASS-42 (Depression, Anxiety and Stress Scale, Lovibond and Lovibond, 1995). We used 10 items from DASS- 42 and adapted them to measure the participants' current state of anxiety. Examples of items are: "I found it difficult to relax", and "I feel upset". This adapted scale showed high reliability for the data used in this study (Table 1). 
For the second part of the study, we developed a measure of illusory pattern perception similarly to Adam Troian et al. (2019) and van Prooijen et al. (2018). We used the website https://www.random.org to create 10 sets of random outcomes of dice throw games. Every set consisted of 10 dicethrow outcomes. Each set was first presented to the participants before they rated the extent to which they believed the sequence was fully random or fully determined. They responded on a 7-point Likert scale, from 1 (completely random) to 7 (completely determined). An example of a dice-throw sequence is shown in Figure 1.

Figure 1: SEQUENCE OF RANDOM DICE THROWS

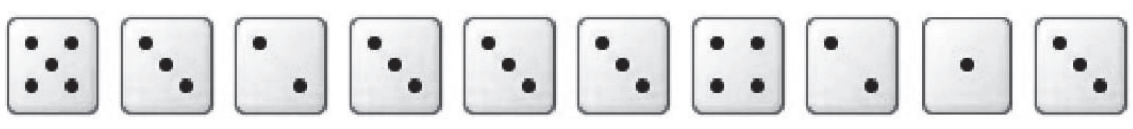

Source: the authors.

In the last part of the study, we measured the tendency for conspiracy beliefs with two complementary measures. The first measure was the Conspiracy Mentality Questionnaire (Bruder et al., 2013), consisting of five items, as a measure of a general tendency to believe in conspiracy theories. Using this measure, participants reported the extent to which they agreed/ disagreed with general beliefs about conspiracy plots by secret groups controlling major events in the world (e.g. "I think that many very important things happen in the world that the public is never informed about", "I think that events which superficially seem to lack a connection are often the result of secret activities"). The questionnaire used an 11-point Likert scale and asked participants to indicate the level of certainty at which they believed the statements to be true ( $0 \%=$ certainly not, $100 \%$ certain). In order to explore the participants' belief in conspiracy theories specifically about Covid-19 as a consequential societal event, we added the second part of the measure. This part contained six statements we developed especially for this study based on conspiracy theories frequently found in public discussion during the spread of SARS-CoV-2, as well as during the presence of vaccinations against it. The items generally cover explanations that the SARS-CoV-2 virus and the vaccines against Covid-19 are the product of secret elites, an experiment by elites and/or scientists, which have the malevolent intention of tracking people and controlling the world using sophisticated biological tools. Examples of items are: "The new mutations of the coronavirus are not random, they are biological weapons produced in a laboratory in order for certain countries to achieve world domination"; "Information about the coronavirus and the delay in the production of vaccines against 
it are a fraud created by pharmaceutical companies, which intend to induce fear and uncertainty among people in order to make a profit". Participants indicated the level of certainty at which they believed these statements to be true using the same 11-point Likert scale used for the Conspiracy mentality questionnaire. We calculated three scores with this measure: two for the sub-scales: Conspiracy mentality and Belief in Covid-19-related conspiracy theories, and a Total score for Conspiracy beliefs. Both sub-scales, as well as the whole scale, showed high reliability for the data in this study (Table 1). Finally, the survey also contained questions on relevant socio-demographic characteristics. At the end of the survey, the participants were thanked and debriefed.

Our data analysis included descriptive statistics calculated for all variables. In order to test the hypothesised relationships between the measures, we used $t$-test, correlation and multiple regression analysis. The statistical analysis was performed with IBM SPSS Statistics (Version 17).

\section{Results and discussion}

Table 1 shows detailed, descriptive information on the variables measured for the two conditions. As seen in the reported arithmetic means, participants in both groups reported high levels for Conspiracy mentality and beliefs in Covid-19-related conspiracy theories, relatively low levels for the anxiety measure, and moderate levels for illusory pattern perception. Table 1 also reveals that all scales and sub-scales have high Cronbach alpha coefficients of reliability.

Correlational analysis was performed on the whole sample containing participants from the two groups. The results presented in Table 2 show that anxiety was significantly correlated with illusory pattern perception and all three conspiracy-related scores (Conspiracy beliefs - total, Conspiracy mentality, and Belief in Covid-19 conspiracy theories). The tendency for illusory pattern perception was significantly correlated with Conspiracy beliefs total and Conspiracy mentality, but surprisingly not with Belief in Covid19 conspiracy theories. Considering the fact that participants reported relatively high scores for Beliefs in Covid-19-related conspiracy theories, as well as taking note of the high correlation between these scores with those for the Conspiracy mentality, we may assume that this result is due to limitations of the method for measuring illusory pattern perception. 
Table 1: DESCRIPTIVE STATISTICS FOR ANXIETY, ILLUSORY PATTERN PERCEPTION AND CONSPIRACY BELIEFS IN HIGH/LOW CONDITIONS OF ANXIETY

\begin{tabular}{|l|l|l|l|l|l|l|}
\hline & $M$ & SD & Min & Max & $\begin{array}{l}\text { No. of } \\
\text { items }\end{array}$ & $\alpha$ \\
\hline Anxiety & & & & & 10 & .83 \\
\hline High-anxiety group & .73 & .34 & .00 & 1.80 & & \\
\hline Low-anxiety group & .36 & .27 & .00 & 1.30 & & \\
\hline $\begin{array}{c}\text { Pattern perception } \\
\text { High-anxiety group }\end{array}$ & 3.62 & 1.02 & 1.40 & 6.37 & 10 & .90 \\
\hline$\quad$ Low-anxiety group & 3.49 & .81 & 1.30 & 5.20 & & \\
\hline $\begin{array}{c}\text { Conspiracy beliefs - total } \\
\text { High-anxiety group }\end{array}$ & 85.40 & 11.17 & 30.00 & 97.00 & 11 & .95 \\
\hline$\quad$ Low-anxiety group & 70.11 & 22.81 & 0.00 & 100.00 & & \\
\hline $\begin{array}{c}\text { Conspiracy mentality } \\
\text { High-anxiety group }\end{array}$ & 84.20 & 11.25 & 40.00 & 96.00 & 5 & .91 \\
\hline Low-anxiety group & 71.77 & 24.95 & 0.00 & 100.00 & & \\
\hline $\begin{array}{c}\text { Belief in conspiracy Covid-19 theories } \\
\text { High-anxiety group }\end{array}$ & 86.39 & 12.62 & 18.00 & 100.00 & 6 & .94 \\
\hline Low-anxiety group & 68.74 & 23.74 & 0.00 & 100.00 & & \\
\hline
\end{tabular}

Note. $(N=187 ; n$ (high-anxiety group $)=97 ; n($ low-anxiety group $=90) ; \mathrm{M}-$ mean; SD - standard deviation; Min/Max - minimum and maximum score; $\alpha$ - Cronbach's reliability coefficient

Source: analysis by the authors.

Table 2: MATRIX OF INTER-CORRELATIONS BETWEEN ANXIETY, ILLUSORY PATTERN PERCEPTION AND CONSPIRACY BELIEFS

\begin{tabular}{|l|l|l|l|l|l|}
\hline Variable & 1 & 2 & 3 & 4 & 5 \\
\hline 1. Anxiety & - & & & & \\
\hline 2. Illusory pattern perception & $.169^{* *}$ & - & & & \\
\hline 3. Conspiracy beliefs - total & $.419^{* * *}$ & $.145^{*}$ & - & & \\
\hline 4. Conspiracy mentality & $.325^{* * *}$ & $.185^{*}$ & $.930^{* * *}$ & - & \\
\hline 5. Believing in Covid-19 conspiracy theories & $.453^{* * *}$ & .098 & $.955^{* * *}$ & $.781^{* * *}$ & - \\
\hline
\end{tabular}

${ }^{*} p<.05 .{ }^{* *} p<.01 .{ }^{* * *} p<.001$

Source: analysis by the authors.

The focal points of the study - results of testing differences in measured variables between the two experimental groups - are presented in Table 3. First, the high value of Cohen's $d$ for anxiety shows the manipulation was very effective, revealing significant differences between the high-anxiety and low-anxiety conditions. The most important finding is that participants in the high-anxiety group reported significantly higher levels for all three conspiracy-related scores (Conspiracy beliefs - total, Conspiracy mentality, and Belief in Covid-19 conspiracy theories). These findings indicate 
the increased levels of anxiety lead to a stronger tendency for conspiracy beliefs in the participants, thereby supporting our main hypothesis. Values of Cohen's $d$ indicate a large effect size, especially for Beliefs in Covid-19 conspiracy theories. Participants in both groups did not differ in their tendency to perceive illusory patterns. This result might be due to the limited sensitivity of the measure for illusory pattern perception.

Table 3: DIFFERENCES IN ANXIETY, ILLUSORY PATTERN PERCEPTION AND CONSPIRACY BELIEFS IN HIGH VS. LOW ANXIETY CONDITIONS

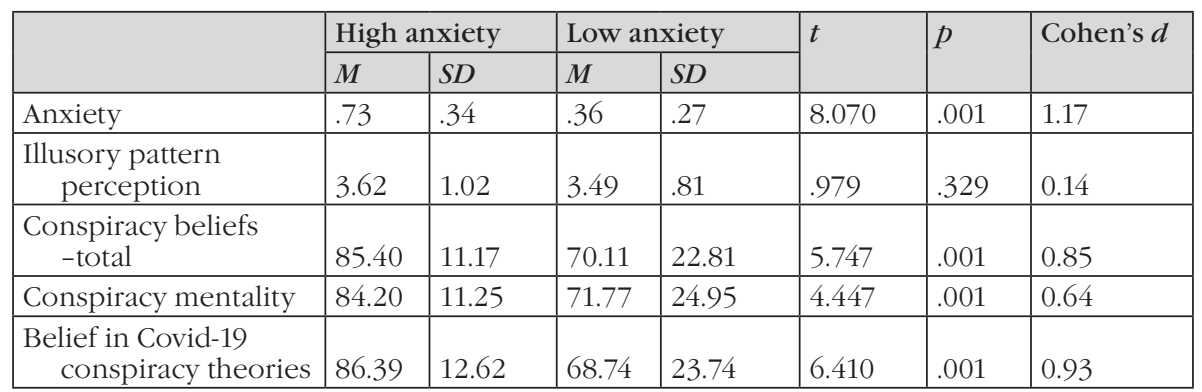

Note. $p<.05$; Cohen's $d$ effect size: $d=0.2$ be considered a 'small' effect size, 0.5 represents a 'medium' effect size and 0.8 a 'large' effect size

Source: analysis by the authors.

Multiple regression analysis of the whole sample was further conducted so as to examine the significance of the predictive model for conspiracy beliefs. The visual inspection of scatterplots confirmed that the relationships between the predictors and outcome variables were linear. The mutual correlations and the values of collinearity statistics for the predictor variables excluded the possibility of collinearity. The PP normal plot and scatterplot suggested the assumptions for conducting the multiple regression analysis were satisfied. The regression analysis showed the tested model is significant $(R=.182 ; F(3,185)=20.41, p<.001)$, yet anxiety was the only significant predictor of Conspiracy beliefs - total, explaining more than $18 \%$ of the variance.

\section{Study 2}

Study 1 showed findings consistent with the relevant literature on the anxiety-conspiracy beliefs relationship. In Study 2, we wanted to explore the causal relationship between illusory pattern perception and beliefs in conspiracies. In this study, we utilised the random dice-throw outcome sequences used in Study 1 in order to manipulate intuitive pattern search. In order to guess the next dice-throw outcome following each sequence, 
participants were either instructed to look for patterns in the dice throws or not to. Based on the findings of Gilovich et al. (1985) and Wilke et al. (2014), we assumed that intuitively searching for patterns in random sequences as a means to guess the next dice-throw outcome would increase people's tendency to perceive illusory patterns in the dice-throw sequences. Our main hypothesis in this study is that a higher intuitive search for patterns in random sequences will increase conspiracy beliefs.

\section{Method}

Participants and design. This study employed a design with two conditions (intuitive pattern search: high vs. low). The same agency collected the data using the same approach as in Study 1. A small-scale representative sample of 204 people participated in the study (96 men, 108 women; $M$ age $=38.26$ years, $S D=12.24$, age range $=18-60$ ). Participants were randomly assigned to the groups. The "high illusory pattern search" group consisted of 101 participants, while the "low illusory pattern search" group included 103 participants. The study took about 15 minutes to complete and participants were rewarded with a small payment. The data were collected soon after the fieldwork in Study 1, with a small chance that any participant would have already been vaccinated by then.

Procedure and measures. The study consisted of two parts. In the first part, participants were asked to play a "dice-throwing game". The aim was to manipulate the intuitive pattern search in two different conditions, similar to van Prooijen et al. (2018). Before starting the dice-throwing game, participants in both groups were instructed that they would participate in a game where they would be shown a sequence of 10 throws of the same dice 10 times, and they would need to try to guess what the next throw would be. The sequences were identical to those used in the pattern perception measure of Study 1. The difference in the treatment (manipulation) between groups was that as instruction continued, the "high intuitive pattern search" condition received the instruction: "Important: Try to see if you can find a pattern in the sequence. Do not try to calculate this, use your intuition. Ask yourself: 'Do I see a pattern in the sequence and, based on that, what next dice outcome would make the most sense?". In the "low intuitive pattern search" condition, participants were given the following instruction: "Important: These are random sequences, generated by the website www.random.org. In a particular sequence, some numbers may be more frequent, which may be expected when a sequence is random. Each dice throw is independent and every number from 1 to 6 has exactly the same probability of $1 / 6$, or $16.7 \%$ of appearing". Participants in both groups were informed that at the end of the game that they would be asked to assess 
how many correct guesses they had made, and that at the end of the study they would be told how accurate their guessing had been. After completing the game, we assessed the participants' tendency to perceive illusory patterns (in order to check if the manipulation was successful) with the following item: "To what extent were the dice-throwing sequences random or revealed a pattern?" $(1=$ they were completely random, $7=$ they completely revealed a pattern).

Participants then continued with the second part of the study, where they were given the same 11-item measure for conspiracy beliefs to complete as in Study 1. Again, both sub-scales, as well as the whole scale, showed high reliability for the data in the study (Table 4). The participants also answered questions about relevant socio-demographic characteristics. Upon completion of the questionnaire, the participants were thanked and debriefed.

\section{Results and discussion}

Table 4 presents descriptive statistics, showing that participants in both groups reported high levels for Illusory pattern perception, and high levels for Conspiracy mentality, and Beliefs in Covid-19-related conspiracy theories. Table 4 also shows that all of the scales and sub-scales used have very high Cronbach alpha coefficients of reliability.

Table 4: DESCRIPTIVE STATISTICS FOR ILLUSORY PATTERN PERCEPTION AND CONSPIRACY BELIEFS IN HIGH VS. LOW CONDITIONS OF INTUITIVE PATTERN SEARCH

\begin{tabular}{|c|l|l|l|l|l|l|}
\hline & $M$ & SD & Min & Max & $\begin{array}{l}\text { number } \\
\text { of items }\end{array}$ & $\alpha$ \\
\hline $\begin{array}{c}\text { Illusory pattern perception } \\
\text { High intuitive pattern search }\end{array}$ & 5.91 & .84 & 4.00 & 7.00 & 1 & - \\
\hline Low intuitive pattern search & 5.03 & 1.26 & 1.00 & 7.00 & & \\
\hline $\begin{array}{c}\text { Conspiracy beliefs - total } \\
\text { High intuitive pattern search }\end{array}$ & 90.73 & 8.05 & 58.00 & 100.00 & 11 & .93 \\
\hline Low intuitive pattern search & 88.20 & 9.73 & 56.00 & 98.00 & & \\
\hline $\begin{array}{c}\text { Conspiracy mentality } \\
\text { High intuitive pattern search }\end{array}$ & 89.50 & 7.87 & 54.33 & 100.00 & 5 & .86 \\
\hline Low intuitive pattern search & 86.35 & 10.33 & 48.00 & 100.00 & & \\
\hline $\begin{array}{c}\text { Belief in Covid-19 conspiracy theories } \\
\text { High intuitive pattern search }\end{array}$ & 91.76 & 9.58 & 57.00 & 100.00 & 6 & .91 \\
\hline Low intuitive pattern search & 89.74 & 10.53 & 53.00 & 100.00 & & \\
\hline
\end{tabular}

Note. $(N=204 ; n$ (high intuitive pattern search group) $=101 ; n$ (low intuitive pattern search group = 103); $M$ - mean; $S D$ - standard deviation; $M i n / M a x-$ minimum and maximum score; $\alpha$ - Cronbach's reliability coefficient Source: analysis by the authors. 
Correlational analysis was applied to the whole sample. It revealed that the tendency for illusory pattern perception was significantly correlated with all of the conspiracy-related scores: conspiracy beliefs total score $(r=$ $.288, p<.001)$, conspiracy mentality $(r=.352, p<.001)$, and belief in Covid19 -related conspiracy theories $(r=.202, p<.01)$.

Table 5 presents results of the analysis of the differences between the manipulation conditions with regard to the measured variables. First, Cohen's $d$ for illusory pattern perception showed a high effect size, meaning the manipulation of intuitive pattern search was very effective. The results further indicated that the increased intuitive pattern search influenced an increase in Conspiracy mentality and the total score for Conspiracy beliefs, although Cohen's $d$ values show a low to moderate effect size. The results also showed there was no significant difference in relation to Beliefs in conspiracy theories concerning Covid-19. In our analysis of this finding, we first note a few related facts: participants in both groups reported high scores for Covid-19-related beliefs in conspiracy theories and, second, the difference between the groups for a Conspiracy mentality, as a measure of the general tendency to believe in conspiracy theories, had a low effect size. We may therefore assume that this result may be explained by the weak relationship between the manipulation for intuitive pattern search and beliefs in Covid19-related conspiracy theories. Most likely, the method for inducing intuitive pattern search does not produce the effect of connecting stimuli when it comes to more complex societal events like explanations of Covid-19 and the vaccines against it. Another possible reason is that at the time the study was being conducted the participants were already over-exposed (desensitised) to the explanations given alongside the scale's statements, and were hence less acceptable to them.

Table 5: DIFFERENCES IN ILLUSORY PATTERN PERCEPTION AND CONSPIRACY BELIEFS IN HIGH VS. LOW INTUITIVE PATTERN SEARCH CONDITIONS

\begin{tabular}{|c|c|c|c|c|c|c|c|}
\hline & \multicolumn{2}{|c|}{ High IPS } & \multicolumn{2}{|c|}{ Low IPS } & \multirow[t]{2}{*}{$T$} & \multirow[t]{2}{*}{$p$} & \multirow[t]{2}{*}{ Cohen's $d$} \\
\hline & $M$ & $S D$ & $M$ & $S D$ & & & \\
\hline $\begin{array}{l}\text { Illusory pattern perception } \\
\text { Conspiracy beliefs - total }\end{array}$ & $\begin{array}{l}5.91 \\
90.73\end{array}$ & $\begin{array}{l}.84 \\
8.05\end{array}$ & $\begin{array}{l}5.03 \\
88.20\end{array}$ & $\begin{array}{l}1.26 \\
9.73\end{array}$ & $\begin{array}{l}5.860 \\
2.021\end{array}$ & $\begin{array}{l}.001 \\
.045\end{array}$ & $\begin{array}{l}0.82 \\
0.28\end{array}$ \\
\hline Conspiracy mentality & 89.50 & 7.82 & 86.35 & 10.33 & 2.447 & .015 & 0.34 \\
\hline $\begin{array}{l}\text { Beliefs in Covid-19 } \\
\text { conspiracy theories }\end{array}$ & 91.76 & 9.58 & 89.75 & 10.51 & 1.427 & .155 & 0.20 \\
\hline
\end{tabular}

Note. $p<.05$; High IPS = high intuitive pattern search, Low IPS = low intuitive pattern search; Cohen's $d$ effect size: $d=0.2$ be considered a 'small' effect size, 0.5 represents a 'medium' effect size and 0.8 a 'large' effect size

Source: analysis by the authors. 


\section{Conclusion $^{1}$}

Many people accept conspiracy beliefs when faced with danger and uncertainty. Psychological theories explain that, in such situations, mechanisms developed over the long history of human life in groups lead us to find answers to the unknown, quickly and in the most economical way. We often use only those elements (information) available to our senses at the moment, regardless of how limited they are or might be. Given the importance of the psycho-sociological phenomenon of conspiracy beliefs, it is necessary to know more about its underlying causal factors. In the search for such factors, in this study we focused on the role of the state of anxiety surrounding uncertain societal events like the Covid-19 pandemic, and the tendency to perceive illusory patterns. Our findings are in accordance with the relevant literature. In Study 1, we manipulated the participants' levels of anxiety, with the results showing that an increase in anxiety leads to an increase in conspiracy beliefs. Correlational analysis showed that anxiety is significantly related to both pattern perception and all three conspiracyrelated measures, and that illusory pattern perception was significantly correlated with a conspiracy mentality and the total score of conspiracy beliefs. In Study 2, we manipulated the participants' intuitive pattern search, where the results revealed that an increase in the tendency to search for and perceive patterns leads to an increase in the general tendency for conspiracy beliefs. Faced with anxious uncertainty, people are more easily attracted to conspiracy beliefs because at the time they provide temporary cognitive and emotional balance.

Our findings in this contribution support the common assumption that people see events in the world as being more strongly causally connected than they really are. People typically underestimate the possibility that the patterns they perceive may actually have occurred completely randomly. These cognitive processes have deep evolutionary psychological roots in the tendency to understand the environment/world, to identify connections between events, and to understand why specific events happen. While drawing such vital conclusions and judgements, especially in a more complex situation under uncertainty, we are not always fully rational. Instead,

1 Limitations: Although the findings clearly confirm the relationship between the variables under study, the methods used to test the causality between intuitive pattern search, and then illusory pattern perception - with complex societal variables as conspiracy beliefs - are still underdeveloped. Considering how important the influences of anxiety and illusory pattern perception are for the processes of judgement-and decision-making, the social sciences require more advanced methods to investigate them. This is especially true knowing that people vary significantly in their sensitivity to experimental manipulations. Another limitation of this study is the specific choice of conspiracy theories concerning Covid-19 used in the scale. While making such choices, the actual context and possible over-exposure to certain explanations should be more carefully considered. 
we use heuristics and other cognitive shortcuts (Kahneman, 2011; Tversky and Kahneman, 1974) that lead us faster to some answer to the unknown. The findings in this study support the notion that anxiety and illusory pattern perception are among the important underlying factors of conspiracy beliefs. We need continued, broader social action if we are to prevent the wide-spreading negative consequences of conspiracy theories.

Conspiracy theories will always exist, especially during crises; the more serious the crisis, the more intensive their production and the speed of their spread. In order to function optimally, people are driven by the need to detect patterns in the environment they interact with. Still, this process sometimes leads them to detect illusory patterns in randomly generated elements and stimuli. Our findings support the assumption that the feeling of anxious uncertainty and the perception of illusory patterns increases the level of conspiracy beliefs. Further research and efforts are needed if we are to prevent their detrimental consequences on the individual and collective levels. Conspiracy theories motivate people to prepare for collective self-defence against suspected subjects or groups (Kofta and Sędek, 2005). Such self-defence could be directed toward health and other authorities and develop into a form of resistance against the vaccination process and other protective measures. Vaccine hesitation is a key problem for the authorities in their efforts to prevent further spread of the new mutation of the virus. Findings in the literature show that beliefs in Covid-19 conspiracy theories were negatively associated with perceived threats caused by the pandemic, complying with government recommendations, and intentions to be vaccinated against Covid-19 (Romer and Jamieson, 2020). On the other hand, they were positively related to aggressive behaviour and support for violence and anti-government protests (Jolley and Paterson, 2020; Šrol et al., 2021), inter-group conflicts, increased prejudice, hostility and discrimination, and the legitimisation of aggression and injustice with respect to the perceived conspirators (Biddlestone et al., 2020).

In order to prevent the development and spread of conspiracy theories, policy creators should play a proactive role. As conspiracy theories are strengthening, it is becoming more difficult for institutions to act fast and effectively enough in their fight against them, precisely because governmental, scientific and health institutions are usually seen as the main malevolent actors believed to be planning harmful actions behind the scenes. The important lesson we have learned is that to be effective in the fight against the damaging effects of conspiracy theories we urgently require both continuous short- and long-term actions in two connected areas: 1 . the communication of information; and 2. education for critical and analytical thinking.

In relation to 1: all relevant crisis-related information should be transparently and timely communicated with the public in a detailed and 
well-thought-out manner, using channels tailored to different clusters of the population. Authorities, in cooperation with scientists, could and should develop strategies and interventions to pre-warn people about misleading information - enabling them to identify conspiracy theories before they are attracted to them. Such measures could prevent anxiety and the tendency to identify patterns in un-connected events. This is because what brings a sense of safety and reduces anxiety in people is probably an acceptable answer which seems logical, and not conspiracy plots themselves (van Prooijen and van Vugt, 2018).

In relation to 2: education should also play an important role in preventing the negative consequences of conspiracy beliefs, particularly in the context of media culture. The findings of some studies show that analytical and critical thinking reduces belief in conspiracy theories (Swami et al., 2014), thus enabling students to distinguish scientific arguments from fake information. In the long term, such interventions would provide a better understanding of science-based information and empower people to deconstruct conspiracy theories.

\section{BIBLIOGRAPHY}

Adam Troian, Jais, Caroti Denis, Arciszewski, Thomas and St hl, Tomas (2019): Unfounded Beliefs Among Teachers: The Interactive Role of Rationality Priming and Cognitive Ability. Applied Cognitive Psychology 33 (4): 720-727.

Bale, Jeffrey (2007): Political Paranoia v. Political Realism: On Distinguishing Between Bogus Conspiracy Theories and Genuine Conspiratorial Politics. Patterns of Prejudice 41: 45-60.

Biddlestone, Mikey, Aleksandra Cichocka, Iris Zezelj and Michal Bilewicz (2020): Conspiracy Theories and Intergroup Relations. In Michael Butter and Peter Knight (eds.), Routledge Handbook of Conspiracy Theories, 219-230. Routledge.

Bruder, Martin, Peter Haffke, Nick Neave, Nina Nouripanah and Roland Imhoff (2013): Measuring Individual Differences in Generic Beliefs in Conspiracy Theories Across Cultures: Conspiracy Mentality Questionnaire. Frontiers in Psychology 4: 225.

Douglas, Karen (2021): COVID-19 Conspiracy Theories. Group Processes and Intergroup Relations 24: 270-275.

Gilovich, Thomas, Robert Vallone and Amos Tversky (1985): The Hot Hand in Basketball: On the Misperception of Random Sequences. Cognitive Psychology 17: 295-314.

Goertzel, Ted (1994): Belief in Conspiracy Theories. Political Psychology 15: 733 744.

Grzesiak-Feldman, Monika (2013): The Effect of High-Anxiety Situations on Conspiracy Thinking. Current Psychology: A Journal for Diverse Perspectives on Diverse Psychological Issues 32 (1): 100-118. 
Haselton, G. Martie and Daniel Nettle (2006): The Paranoid Optimist: An Integrative Evolutionary Model of Cognitive Biases. Personality and Social Psychology Review 10 (1): 47-66.

Jolley, Daniel and Jenny L. Paterson (2020): Pylons ablaze: Examining the role of 5 G COVID 19 Conspiracy Beliefs and Support for Violence. British Journal of Social Psychology 59 (3): 628-640.

Kahneman, Daniel (2011): Thinking, Fast and Slow. New York: Farrar, Straus and Giroux.

Kofta, Miroslaw and Grzegorz Sedek (2005): Conspiracy Stereotypes of Jews during Systemic Transformation in Poland. International Journal of Sociology 35: 40-64.

Leman, Patrick (2007): The Born Conspiracy. New Scientist 195: 35-37.

Lerner, Jenifer S. and Dacher Keltner (2001): Fear, Anger, and Risk. Journal of Personality and Social Psychology 81 (1): 146-159.

Lovibond, Syd and Peter Lovibond (1995): Manual for the Depression Anxiety Stress Scales (2nd. ed.). Sydney: Psychology Foundation

Moscovici, Serge (1987): The Conspiracy Mentality. In Carl Graumann and Serge Moscovici (eds.), Changing Conceptions of Conspiracy, 151-169. Springer.

Rządeczka, Marcin (2018): 'When Being Right is Not Good Enough: How Systematic Cognitive Biases Affect Decision Making Strategies'. In Rationality and Decision Making 111: 240-252. Leiden, The Netherlands: Brill.

Romer, Daniel and Kathleen Jamieson (2020): Conspiracy theories as Barriers to Controlling the Spread of COVID-19 in the US. Social Science and Medicine 263: Article 113356.

Spasovski, Ognen and Kenig Nikolina (2020): Psychological Well-Being in Students during Self-Isolation Due to the Covid-19 Pandemic. Primenjena Psihologija 13 (4): 427-447.

Šrol, Jakub, Vladimira Cavojova and Mikušková B. Eva (2021): Social Consequences of COVID-19 Conspiracy Beliefs: Evidence from two studies in Slovakia. PsyArXiv Preprints.

Swami, Viren, Martin Voracek, Stefan Stieger, Tran S. Urlich and Adrian Furnham (2014): Analytic Thinking Reduces Belief in Conspiracy Theories. Cognition 133 (3): 572-585.

Tversky, Amos and Daniel Kahneman (1974): Judgment under Uncertainty: Heuristics and Biases. Science 185 (4157): 1124-1131.

Václaviková, Ivana and Lenka Selecká (2018): Anti-vaccination Information's (Not-) Trustworthiness: Selected Personality Traits and Emotional Context. Education, Culture and Identity. Sarajevo: International University of Sarajevo.

Václaviková, Ivana, Lenka Selecká and Fábry Rudolf (2016): How the (Anti)Vaccine Information Credibility Could be Changed? The Importance of Personality Traits, Attitudes and Expert Source Presence. GRANT journal 5 (2): 82-85.

Van Prooijen, Jan Willem (2020): An Existential Threat Model of Conspiracy Theories. European Psychologist 25 (1): 16-25.

Van Prooijen, Jan Willem, Karen Douglas and Clara De Inocencio (2018): Connecting the Dots: Illusory Pattern Perception Predicts Belief in Conspiracies and the Supernatural. European Journal of Social Psychology 48 (3): 320-335. 
Van Prooijen, Jan Willem and Van Vugt Mark (2018): Conspiracy Theories: Evolved Functions and Psychological Mechanisms. Perspectives on Psychological Science 13 (6): 770-788.

West, G. Harry and Sanders Todd (2003): Transparency and Conspiracy: Ethnographies of Suspicion in the New World Order. Duke University Press.

Wilke, Andreas, Scheibehenne, Benjamin, Gaissmaier, Wolfgang, McCanney, Paige and Barrett, H. Clark (2014): Illusory Pattern Detection in Habitual Gamblers. Evolution and Human Behavior 35: 291-297.

Whitson, A. Jenifer and Adam D. Galinsky (2008): Lacking Control Increases Illusory Pattern Perception. Science 322(5898): 115-117. 